\title{
Correlation Between Demographic Perspective of PG Trainees and Research: A Cross-Sectional Multidisciplinary Study
}

Nabiha Farasat Khan ${ }^{1}$

Muhammad Saeed ${ }^{2}$

Usama Saeed ${ }^{3}$

\author{
BDS, M.Phil, MHPE \\ BDS
}

MBBS

OBJECTIVE: Demographic perspectives of future investigators (PG trainees of Medicine \& Dentistry) have more or less effect on their achievements. Such perspectives may also work as barriers towards scientific activities. The aim of the study is to evaluate whether (if any) demographic perspectives working as barrier in research work among PG trainees.

METHODOLOGY: To assess the effects of demographic view on the research activities of 72 PG trainees a cross-sectional survey was carried out at 3 different public sector medical and dental institutes (Bolan Medical Complex Hospital (BMCH), Quetta Institute of Medical Sciences (QIMS) and Institute of Public Health (IPH) within 3 months (May-July 2018). Data was collected and analyzed by using SPSS version 20. A p-value of $<0.05$ was considered significant.

RESULTS: Sixty-one percent of the study participants were males. Almost half (43\%) PG trainees demonstrated positive attitude towards item number 3 "students can plan \& conduct scientific research" (Mean \pm SD4.36 \pm .65 ), 86.1\% agreed to accomplish research work at undergraduate level, even in the absence of a supervisor (p-0.004). Low father educational level induces a lack of interest in PG trainees research work ( $\mathrm{p}-0.01$ ), whereas PG trainees having illiterate mothers present a strong correlation between lack of research work and un co-operative faculty $(\mathrm{p}<0.001)$ which creates hurdle in their scientific activities. CONCLUSION: PG trainees of Pakistani community demonstrates positive attitude towards research activities. They express keenness regarding scientific task but due to low parental education level they face un-cooperative faculty which intern reduces their interest in research work. Whereas over-loaded curriculum, social and family commitments and job duties medical PG's face time management issues.

KEY WORDS: Demographic perspective, PG trainees, Dentistry, Medicine, Hurdles, Research.

HOW TO CITE: Khan NF, Saeed M, Saeed U. Correlation between demographic perspective of pg trainees and research: A cross-sectional multidisciplinary study. J Pak Dent Assoc 2020;29(1):24-29.

DOI: https://doi.org/10.25301/JPDA.291.24

Received: 26 April 2019, Accepted: 04 October 2019

\section{INTRODUCTION}

$\mathrm{R}$ esearch is an essential element in promotion and betterment of patient's care and health system through bridging the gap between basic and clinical sciences. ${ }^{1}$ Components of research (systematic literature search, critical appraisal, independent learning and scientific paper writing) enhance physician skills, amplify under/postgraduate medical student's scientific knowledge, help to figure out issues and works as main incentive guaranteeing the key growth scale. ${ }^{2-5}$ Globally, many developed and under developed countries have implemented compulsory courses that flourish and nurture positive attitude towards research. ${ }^{6}$ Regardless of its importance, various

1. Associate Professor, Department of Oral Pathology, Bolan Medical College, Quetta.

2. Senior Demonstrator, Department of Prosthodontics, Bolan Medical College, Quetta.

3. Student 2nd Year, Dow Medical College, Karachi.

Corresponding author: "Dr. Nabiha Farasat Khan” < nabihasaeed@ hotmail.com > researchers have pointed out barriers against scientific research so the number of researchers continues to dwindle worldwide, ${ }^{7-13}$ Although investigators recognize barriers towards research work, however none of them has investigate the role of demographic view (age, gender, marital status and maternal education) on research work among PG trainees of medicine \& dentistry. This study was therefore started to evaluate the effects of demographic views on research activities among postgraduate medical and dental students in 3 public center medical institutes.

\section{METHODOLOGY}

A questionnaire based cross-sectional survey was carried out on 72 PG trainees of Bolan Medical Complex Hospital (BMCH), Quetta Institute of Medical Sciences (QIMS) and Institute of Public Health (IPH). Permission to conduct the study was granted by the principal Bolan Medical College, 
Quetta. All participants working as PG trainees in $\mathrm{BMCH}$, QIMS \& IPH were included in the study, whereas house officers were excluded from study. A demonstrator from dental section distributed \& collected validated questionnaire formulated by Amin $\mathrm{TT}^{8}$ which recorded PG trainee's demographic views (age in years, gender, parental education status, marital status, type of schooling). Confidentiality was confirmed. Attitudes and perceptions about research barriers were recorded with 16 questions using a Five point Likert scale; $1=$ Strongly Disagree $(\mathrm{SD}) 2=$ Disagree $(\mathrm{D}), 3=$ Neutral (N), 4= Agree (A), 5= Strongly Agree (SA) to assess trainee's responses. Likert scale variables were recoded for further analysis by combining categories agree and strongly agree in to a single group agree recoded 3, categories strongly disagree and disagree into a single category disagree coded as 1 while neutral was retained and coded as 2 . Higher the score, higher the attitude level and thus, barrier was measured. The information collected was analyzed by using statistical software SPSS-20.

Chi-square test was used to evaluate association between research barriers and demographic details. Normality assumption was evaluated with Kolmogorov-Smirnov test.

\section{RESULTS}

There were 80 PG trainees, 8 of them were absent at the time of data collection giving $90 \%$ response rate. Out of these remaining $72 \mathrm{PG}$ trainees $38(52.77 \%)$ participants belonged to $\mathrm{BMCH}, 15$ (20.83\%) from QIMS and 19 (26.38\%) were MBBS doctors of IPH. Majority (61.1\%) were males and between 28-30 years of age (mean age of

Table 1: Demographic view of PG Trainees from BMCH, CMH \& IPH

\begin{tabular}{|c|c|c|c|c|}
\hline \multirow[t]{2}{*}{ Characteristics } & \multicolumn{4}{|c|}{ Institutes } \\
\hline & $\begin{array}{l}\text { IPH } \\
\text { n(\%) }\end{array}$ & $\begin{array}{l}\text { BMCH } \\
\text { n(\%) }\end{array}$ & $\begin{array}{l}\text { QIMS } \\
\text { n(\%) }\end{array}$ & $\begin{array}{l}\text { Total } \\
\text { N (\%) }\end{array}$ \\
\hline \multicolumn{5}{|l|}{ Gender } \\
\hline Males & $12(16.66)$ & $24(33.33)$ & $8(11.11)$ & $44(61)$ \\
\hline Females & $7(10)$ & $14(19.44)$ & $7(10)$ & $28(39)$ \\
\hline Age in years (Mean \pm SD) & \multicolumn{4}{|l|}{$23.3 \pm 4.6$} \\
\hline \multicolumn{5}{|l|}{ Year of Enrollment } \\
\hline $1^{\text {st }}$ year & $11(15.27)$ & $8(11.11)$ & $5(7)$ & $24(33.33)$ \\
\hline $2^{\text {nd }}$ year & $8(11.11)$ & $11(15.27)$ & $4(5.55)$ & $23(32)$ \\
\hline $3^{\text {ra }}$ year & - & $2(3)$ & $1(1.38)$ & $3(4.16)$ \\
\hline Final year & - & $17(23.16)$ & $5(7)$ & $22(30.55)$ \\
\hline \multicolumn{5}{|l|}{ Type of Schooling } \\
\hline Public & $8(18.18)$ & $9(20.45)$ & $27(61.36)$ & $44(61.11)$ \\
\hline Private & $11(25)$ & $6(13.63)$ & $11(25)$ & $28(39)$ \\
\hline \multicolumn{5}{|l|}{ Father Educational Status } \\
\hline Illiterate & $4(5.55)$ & $2(2.77)$ & 0 & $6(8.33)$ \\
\hline Read \& write & 0 & $3(4.16)$ & $1(1.38)$ & $4(5.55)$ \\
\hline Primary & $1(1.38)$ & $1(1.38)$ & $1(1.38)$ & $9(12.5)$ \\
\hline Secondary & $2(3)$ & $5(7)$ & $2(3)$ & $9(12.5)$ \\
\hline College & $6(8.33)$ & $12(16.66)$ & $6(8.33)$ & $24(33.33)$ \\
\hline Higher Education & $6(8.33)$ & $9(12.5)$ & $5(7)$ & $20(28)$ \\
\hline \multicolumn{5}{|l|}{ Mother Educational Status } \\
\hline Illiterate & 0 & $15(20.83)$ & $3(4.16)$ & $18(25)$ \\
\hline Read \& write & $1(1.38)$ & $7(10)$ & $3(4.16)$ & $11(15.27)$ \\
\hline Primary & $3(4.16)$ & $8(11.11)$ & $1(1.38)$ & $12(16.66)$ \\
\hline Secondary & $5(7)$ & $4(5.55)$ & $2(3)$ & $11(15.27)$ \\
\hline College & $6(8.33)$ & $4(5.55)$ & $3(4.16)$ & $13(18.05)$ \\
\hline Higher Education & $4(5.55)$ & 0 & $3(4.16)$ & $7(10)$ \\
\hline
\end{tabular}

$23.3 \pm 4.6$ years). Detailed demographic data of participants is presented in Table 1.

Table 2 demonstrate the distribution of scores on attitudes and perceptions about barriers in scientific research among the dental and medical PG trainees. PG trainees exhibited willingness to conduct research (Mean \pm SD 4.36 \pm .65$)$ mean while they noticed lack of lab \& other facilities as major

Table 2: Distribution of scores on Attitudes and Perceptions about Barriers in scientific research among the dental and medical postgraduate trainees

\begin{tabular}{|c|c|c|c|c|}
\hline $\begin{array}{l}\text { Attitudes towards research scores } \\
\text { 1. Confident in interpreting and writing a } \\
\text { research paper }\end{array}$ & $\begin{array}{l}\text { Min } \\
1.00\end{array}$ & $\begin{array}{l}\text { Max } \\
5.00\end{array}$ & $\begin{array}{l}\text { Mean } \\
3.77\end{array}$ & $\begin{array}{l} \pm \text { S.D } \\
1.05\end{array}$ \\
\hline $\begin{array}{l}\text { 2. Undergraduate students should participate in } \\
\text { research }\end{array}$ & 1.00 & 5.00 & 4.09 & 0.82 \\
\hline $\begin{array}{l}\text { 3. Undergraduate students can plan and conduct a } \\
\text { research project and write a scientific paper }\end{array}$ & 1.00 & 5.00 & 3.51 & 1.18 \\
\hline $\begin{array}{l}\text { 4. Medical students can plan and conduct research } \\
\text { without supervisor }\end{array}$ & 1.00 & 5.00 & 2.79 & 1.31 \\
\hline 5. Willingness to conduct clinical research & 3.00 & 5.00 & 4.36 & 0.65 \\
\hline $\begin{array}{l}\text { 6. Willingness to conduct community based } \\
\text { research }\end{array}$ & 1.00 & 5.00 & 4.09 & 1.02 \\
\hline Barriers to research scores & Min & Max & Mean & \pm S.D \\
\hline 1. Lack of proper mentoring from faculty & 1.00 & 5.00 & 4.12 & 0.99 \\
\hline 2. Uncooperative faculty & 1.00 & 5.00 & 3.83 & 0.91 \\
\hline 3. Lack of time & 1.00 & 5.00 & 4.23 & 0.91 \\
\hline 4. Lack of proper lab and other facilities & 2.00 & 5.00 & 4.30 & 0.76 \\
\hline 5. Deficient faculty research knowledge and skill & 1.00 & 5.00 & 3.87 & 1.04 \\
\hline 6. Inaccessibility of electronic and medical data & 1.00 & 5.00 & 4.00 & 0.97 \\
\hline 7. Lack of funding & 1.00 & 5.00 & 3.86 & 1.17 \\
\hline 8. Lack of motivation and or rewarding & 2.00 & 5.00 & 4.23 & 0.77 \\
\hline $\begin{array}{l}\text { 9. Lack of appropriate knowledge and skill of } \\
\text { research }\end{array}$ & 1.00 & 5.00 & 3.79 & 1.00 \\
\hline 10. Lack of interest & 1.00 & 5.00 & 3.38 & 1.32 \\
\hline
\end{tabular}

Table 3: Presenting association between research barrier \& demographic view

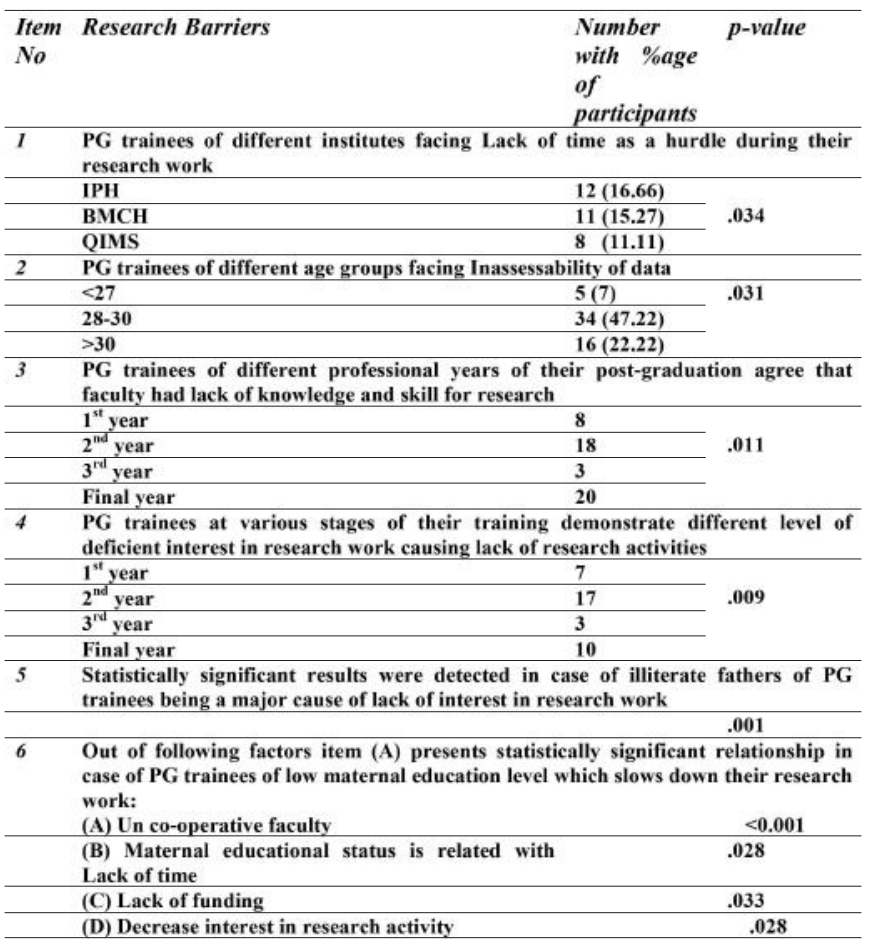


hurdle in their research activities (Mean \pm SD 4. 30) whereas lack of time, motivation and/or reward also becomes an issue among PG trainees towards their scientific approach (Mean \pm SD $4.23 \pm 0.91 \& 4.23 \pm 0.77$ respectively).

Attitudes and barriers scores of PG trainees in relation to socio-demographic and personal characteristics response rate is presented in Table 3. Low father educational level decreases PG trainees interest in research (p-0.01) whereas statistically significant correlation was found between low mother educational level and un co-operative faculty

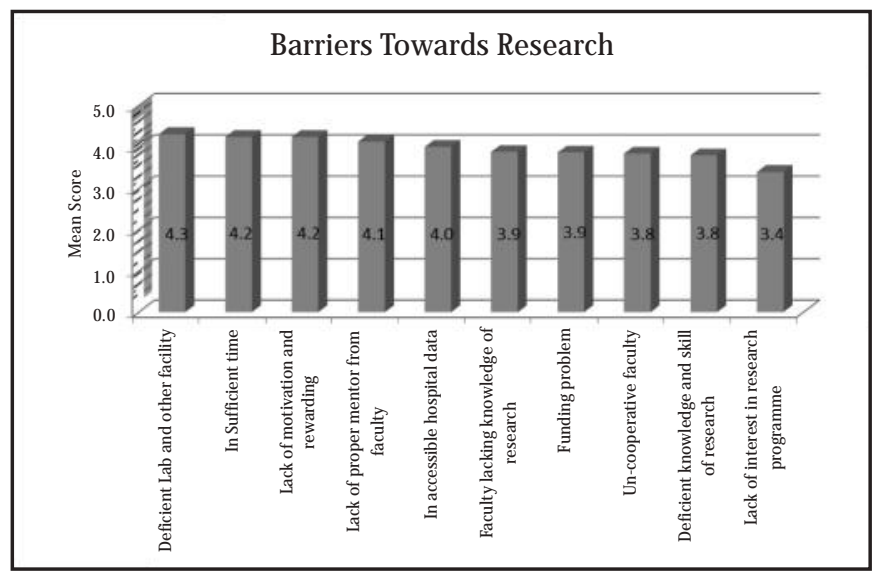

Bar Chart presenting barriers towards research work among PG trainees of Medicine \& Dentistry

(p-<0.001) causing deficient interest in research of PG trainees. Strong co-relation was also observed between undergraduate participation and their views about ready to conduct research in the absence of supervisor (p-0.004), whereas no correlation was observed between age and attitude and research barriers among PG trainees. Likewise schooling and marital status didn't effect PG trainees research work.

Bar chart presented barriers towards research work among PG trainees of medicine \& dentistry.

\section{DISCUSSION}

This study aims to highlight the obstacles faced by local postgraduate residents in conducting research with an aim to improve research productivity and overall health care in the field of dentistry.

This study evaluates outcome of demographic role of local PG trainees on research work with the aim to ameliorate research efficacy which would exhibit outcome in the field of medicine \& dentistry. In developed countries like Canada \& US research is mandatory, ${ }_{14}^{14}$ however controversy exist between developed and under developed countries as in India 91\% PG trainees did not demonstrates research work during their PG training. ${ }^{15}$ On the other hand Pakistani students express their interest in scientific activities as $68.7 \%$ medical students participated in research work, ${ }^{6}$ however as research is not essential nor mandatory for medical students; research work ratio is still unsatisfactory. ${ }^{1,16}$ The main reason behind this deficient research work in developing countries is limited financial sources also lack of research skills and work senior faculty member do not have enough experience in research skills and writing which affecting in mentoring the new researchers. Therefore, new policies of PMDC and HEC are forcing the PG trainees to take interest in research. Moreover, students financial support for research enhance student participation in research activities. Thus paying special attention to students' research budgets increases chance of student participation in the research works. ${ }^{2}$

Poverty, lack of resources, poor access to the literature, and poor knowledge about the research. ${ }^{17,18}$ created a large disparity in research productivity in low-income areas of the country such as in Balochistan. Research is not a high priority for medical students of this province to carry out; even then participants of our study demonstrated positive attitude towards research work by accepting the beneficial role of research in their medical education. Highest mean score was detected on item number 5 "students carry out clinical research" (Mean \pm SD $4.36 \pm 0.65)$. Same results were identified worldwide as other researcher also declare medical students interest in scientific activities. ${ }^{8,19-21}$ Amin TT, Khan H \& Aslam A identified significant improvement in the attitudes of medical students with increasing years of study in medical college. ${ }^{8,14,19}$ Whereas in Morae's study, participants presented highest interest $(81.7 \%)$ in research activities. ${ }^{20}$ This positive attitude towards research is a response to early exposure to research methodology \& its importance, introduction \& participation in workshops \& conferences which enhance interest of under-graduate medical students in research work. ${ }^{22}$

Researchers noticed a significant effect of parental education on their children's educational attainment, that effects on their mind setup providing a positive outcome that improves opportunities and decision making abilities and influences their children's achievements. Results demonstrates a positive outcome, as environment created by educated parents ameliorate the chances for their children and decision process. ${ }^{23,24}$ Research proved positive correlation regarding the impact of family involvement on educational outcomes. ${ }^{24}$ This was confirmed in our study as a strong correlation was observed between PG trainees father educational level and lack of interest in their research work (p-.001). On contrary Amin TT recognized 56.3\% highly qualified fathers of his study participants. The reason of this two-fold difference is low literacy rate of males (39\%) in Balochistan. ${ }^{25}$ 
Chevalier detected a positive relation between maternal education and her offspring's education..$^{23}$ In Saudia Arabia $46 \%$ mothers were highly qualified. ${ }^{8}$ Unfortunately this phenomenon was not true in case of our study as $25 \%$ mothers of our study participants were illiterate and the ratio of highly qualified mothers was very low (only 10\%) demonstrating almost doubled difference with well-known cause; very low female literacy rate in Balochistan (16\%). We also noticed statistically significant results in case of PG trainees of uneducated mother facing un co-operative faculty ( $\mathrm{p}-<0.001)$. This is because the children belonging to uneducated parents are shy and less competent, unable to deal and explain their views to others. ${ }^{26}$ Researchers found highly qualified mothers exhibiting more positive beliefs, expressing higher expectations for their children's academic achievement and these expectations are related to their children's subsequent achievements. Moreover, mothers' education is predictive of parental warmth. ${ }^{24}$

Subsequent deficiency in research knowledge and skills of physicians could have negative effects on educational, clinical research and health care, shortening the translation of bridging between basics and clinical work. ${ }^{27}$ This fact was confirmed in current study as our findings demonstrated inadequate skill and knowledge of research of the faculty as a main personal barrier towards research (p-0.011). On the other hand, 37.1\% ( $\mathrm{n}=157 / 423)$ participants of Amin TT realizes faculty low research knowledge and skill reduces their involvement in scientific activities. ${ }^{8}$ In our research 24 $\%$ PG trainees feels lack of interest causing deficient research activities (p-.009), other studies also detected the origin of deficient interest in research is lack of motivation or shortage of funding, over loaded curriculum, ${ }^{13}$ time management, ${ }^{2,28}$ or lack of supervisor/mentor and/or limited facilities and high work load. ${ }^{2,29}$ Attractive stipend/scholarship, review/reformation of curriculum and trained and easy availability of supervisor/mentor, enrollment early in research of medical students have been recommended that can boost interest of under/postgraduate medical and dental students in scientific activities and assists undergraduate medical students to engage in research during their graduation which would make them able to conduct research easily in their post-graduation. ${ }^{27}$ Medical and electronic data availability assist in discovering knowledge gap thus helps PG trainees to initiate their research work. The students cited bounded approach to the relevant medical and other electronic databases made them difficult to initiate their research activities. ${ }^{4}$ PG trainees of current research also disclose the fact that restricted approach of relevant electronic and medical databases is inconvenient for them to work on knowledge gap (p-0.31). ${ }^{4}$ Poor economy \& poverty may be a major cause of this problem in developing countries whereas this is not observed in developed countries. ${ }^{8}$

A number of barriers exhaust and discourage medical students to continue research activities. Time was seen to be a significant barrier to pursue research interest. Mohammad Ismial from Ireland recognized only $23 \& 28$ $\%$ medical students feeling easy to continue their research work with adequate time. ${ }^{30}$ On the other hand, in current research work we recognized $63 \%$ PG trainees $(n=12 / 19)$ of medicine from IPH faces "Lack of time" to complete their research work (p-.034). The respondents of other research studies supported our observations where students reported lack of time as a major obstacle. ${ }^{4,8,11,13}$ Medical students declare lengthy medical curriculum and intense terms of contact hours as a main reason behind not participating in scientific work. Similarly, it was the main issue of Amin research participants where time management was a major obstacle in their research work $(62.4 \%) .{ }^{8}$ Likewise Funston detected lack of time a 2nd major obstacle in research activities of his respondents. ${ }^{9}$ In comparison Pearson detected $84 \%$ students endorsed insufficient time to participate in research. This concern can be overcome through slotting a proper time in curriculum for research work.

\section{STRENGTH \& WEAKNESSES OF WORK}

Although Pakistani researchers evaluate attitude and barriers of research among medical students of Punjab, KPK and Karachi however to the best of our knowledge this research is the first to assess the demographic role on attitude and find barriers of research among medical and dental PG trainees in Balochistan which is one of the most important strategical site in the world but unfortunately, also a least developed and most backward province in the country. This research utilized self-reported questionnaire in which response rate may result in possible selection bias. Another limitation was that PG trainees of different departments face divergent obstacles which might not be discussed in the study. Further research can be undertaken in a more rigorous manner by increasing the sample size and using a more scientific approach. In addition, it could have been more interesting to survey the research hurdles with more generalized results obtained through conducting this research on medical students studying in Makran Medical College Turbat, Jhalwan Medical College Khuzdar and Lorali Medical College of Balochistan.

\section{CONCLUSION}

Majority of PG trainees accept the importance of research and its advantage in future through demonstrating good 
attitude towards research work. However, maternal education, faculty's inadequate skills and knowledge in research, lack of interest, limited access to information sources, limited facilities and time management are the main barriers to research in medicine and dentistry PG trainees.

\section{RECOMMENDATIONS}

Conducting theoretical and practical research methodology courses/workshops, forming a responsive and helpful research team assistant to support students and providing them required facilities/equipment, and giving financial support for the student's research activities in form of stipend/scholarship can help to remove the existing barriers to research. Young researchers should be encouraged through attractive stipend/scholarship, conduction of conferences and research workshops to enhance their interest in research work. Faculty development programmes to improve research culture and increase students' motivation and participation can be initiated.

\section{ACKNOWLEDGEMENT}

We are grateful to the PG trainees of BMCH, QIMS \& IPH for their voluntarily participation in assessing hurdles towards scientific activities among PG trainees of dental and medical institutes.

\section{FUNDING RESOURCES}

None

\section{CONFLICT OF INTEREST}

None declared

\section{REFERENCES}

1. Farrukh M. Lack of Research Interest among Medical Students: Causes and Consequences. Annals of Abbasi Shaheed Hospital and Karachi. Med Dent Col. 2013;18:54-5.

2. Dadipoor S, Ramezankhani A, Aghamolaei TA, Safari-Muradabadi. Barriers to research activities as perceived by medical university students: A cross-sectional study. Avicnna J Med. 2019; 9: 8-14.

3. Minai FN. Professionalism in residency training. J Coll Physicians Surg Pakistan. 2009;19: 675-7.

4. Soe HHK, Than NN, Lwin H, Htay MNN, Phyu KL, Abas AL. Knowledge, attitudes, and barriers toward research: The perspectives of undergraduate medical and dental students. J Educ Health Promot. 2018;7:23.

https://doi.org/10.4103/jehp.jehp_61_17
5. Noorelahi MM, Soubhanneyaz AA, Kasim KA. Perceptions, barriers, and practices of medical research among students at Taibah College of Medicine, Madinah, Saudi Arabia. Adv Med Educ Pract. 2015; 6: 479-85.

https://doi.org/10.2147/AMEP.S83978

6. Jeelani W, Jeelani W, Aslam SM, Elahi A. Current trends in undergraduate medical and dental research?: a picture from Pakistan current trends. J Ayub Med Coll Abbottabad. 2014;26:162-66.

7. Kahn K, Ryan G, Beckett M, Taylor S, Berrebi C, Cho M, et al. Bridging the gap between basic science and clinical practice: a role or community clinicians. Implement Sci. 2011;6:34.

https://doi.org/10.1186/1748-5908-6-34

8. Amin TT, Kaliyadan F, Al Qattan EA, Al Majed MH, Al Khanjaf HS, Mirza M. Knowledge, attitudes and barriers related to participation of medical students in research in three Arab Universities. Educ Med J 2012;4: 43-56.

https://doi.org/10.5959/eimj.v4i1.7

9. Funston G, Piper RJ, Connell C, Foden P, Young a MH, O'Neill P. Medical student perceptions of research and research-orientated careers: An international questionnaire study. Med Teach 2016;38:1-8. https://doi.org/10.3109/0142159X.2016.1150981

10. Sheikh ASF, Sheikh SA, Kaleem A, Waqas A. Factors contributing to lack of interest in research among medical students. Adv Med Educ Pract 2013;4:237-43.

https://doi.org/10.2147/AMEP.S51536

11. AlGhamdi KM, Moussa NA, AlEssa DS, AlOthimeen N, Al-Saud AS. Perceptions, attitudes and practices toward research among senior medical students. Saudi Pharm J. 2014;22:113-17.

https://doi.org/10.1016/j.jsps.2013.02.006

12. Abushouk AI, Hatata AN, Omran IM, Youniss MM, Elmansy KF, Meawad AG. Attitudes and Perceived Barriers among Medical Students towards Clinical Research: A Cross-Sectional Study in an Egyptian Medical School. J Biomed Educ. 2016; Article ID 5490575, 7 pages. https://doi.org/10.1155/2016/5490575

13. Imran Saeed, Khan NF, Bari A, Khan RA. Factors contributing to the lack of interest in research activities among postgraduate medical students. Pak J Med Sci. 2018;34:913-17.

https://doi.org/10.12669/pjms.344.15411

14. Aslam A. Research Challenges for Postgraduate Residents in Dentistry. Pakistan Oral Dent J. 2017;36:683-87.

15. Baig SA, Hasan SA, Ahmed SM, Ejaz K, Aziz S. Reasons Behind the Increase in Research Activities Among Medical Students of Karachi, Pakistan , a Low-Income Country. Educ Health. 2013; 26:117-21.

https://doi.org/10.4103/1357-6283.120705

16. Council D, Commission HE. PMDC BDS curriculum. 2003; 67.

17. Salam N. Balochistan Strategy Pakistan Poverty Alleviation Fund. 
Balochistan Strategy: a road map to inclusive socio-economic development for the province. 2013. p. 1-110.

18. Safdar P, Ikram K, Noshab F, Ahmed M. Pakistan - Balochistan Economic Report: From Periphery to Core, Volume 1. Summary Report. 2008.

19. Khan H, Khawaja MR, Waheed A, Rauf MA, Fatmi Z. Knowledge and attitudes about health research amongst a group of Pakistani medical students. BMC Med Educ 2006;6:54.

https://doi.org/10.1186/1472-6920-6-54

20. Moraes DW, Jotz M, Menegazzo WR, Menegazzo MS, Veloso S, Machry MC, et al. Interest in research among medical students: Challenges for the undergraduate education. Rev Assoc Med Bras 2016;62:652-58.

https://doi.org/10.1590/1806-9282.62.07.652

21. Alsied SM, Ibrahim NW. Exploring Challenges Encountered by EFL Libyan Learners in Research Teaching and Writing. IAFOR J Lang Learn 2017; 3:143-58.

https://doi.org/10.22492/ijll.3.2.06

22. Bhalerao S, Prasad BS. Journal of Ayurveda and Integrative Medicine Attitude of interns towards research as a career option. J Ayurveda Integr Med 2016;7:76-7.

https://doi.org/10.1016/j.jaim.2015.06.001

23. Chevalier A. Parental Education and Child ' s Education: A Natural Experiment. IZA Discuss Pap. 2004; (1153): 1-30.

24. Davis-kean PE. The Influence of Parent Education and Family Income on Child Achievement: The Indirect Role of Parental Expectations and the Home Environment. J Fam Psychol. 2005;19:
294-04.

https://doi.org/10.1037/0893-3200.19.2.294

25. Magsi J, Khail M, Abdullah K. Literacy rate and education. http://balochistan.gov.pk/mics/MICS-4-Web/4-1-ResultsLiteracy\%20\&\%20Education. 2004;29-42.

26. Ghaffar A, Shah FA, Mehmood S, Idrees M, Zaman A, Ali R, et al. Following Them in the Footprints: The Effect of Parental Illiteracy on the Drop-Out of Their Children. World Appl Sci J. 2013;23:18-23.

27. Stockfelt M, Karlsson L, Finizia C. Research interest and activity among medical students in Gothenburg, Sweden , a cross-sectional study. BMC Med Educ BMC Medical Education; 2016;16:226. https://doi.org/10.1186/s12909-016-0749-3

28. Jeje EA, Elebute OA, Mofikoya BO, Ogunjimi MA, Alabi TO. Research experience of resident doctors who attended research methodology courses of the National Postgraduate Medical College of Nigeria. Niger Postgrad J. 2017;

24:31-6.

https://doi.org/10.4103/npmj.npmj_153_16

29. Aslam F, Shakir M, Qayyum MA. Why Medical Students Are Crucial to the Future of Research in South Asia. PLoS Med. 2005; 2: 1110-1.

https://doi.org/10.1371/journal.pmed.0020322

30. Ismail IM, Bazli MY, Flynn SO. Study on Medical Student ' s Attitude Towards Research Activities between Study on medical student ' $\mathrm{s}$ attitude towards research activities between University College Cork and Universiti Sains Malaysia. Procedia - Soc Behav Sci [Internet]. Elsevier B.V 2015;116:2645-9.

https://doi.org/10.1016/j.sbspro.2014.01.628 